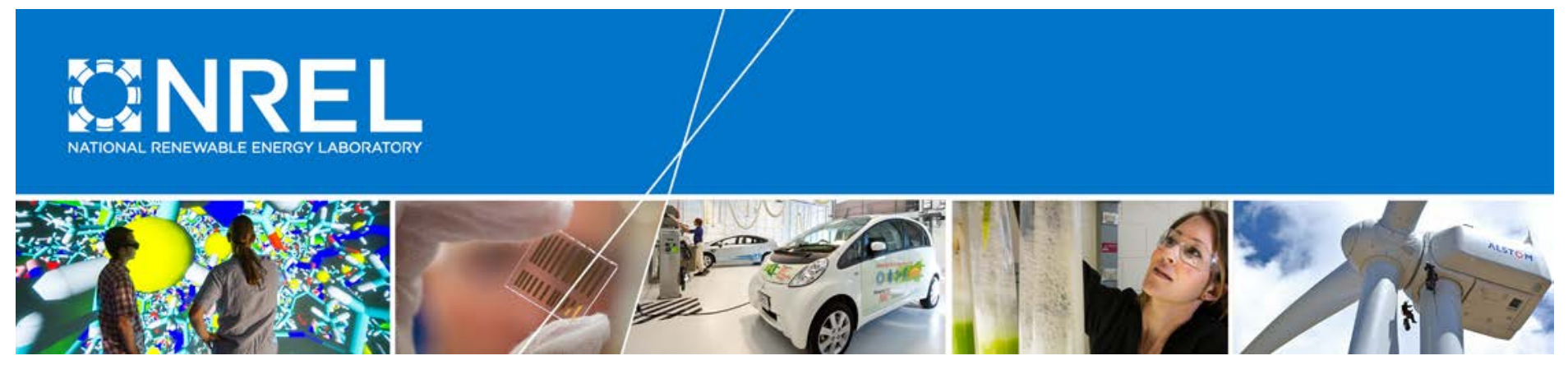

\title{
Predicting the Response of Electricity Load to Climate Change
}

Patrick Sullivan, Jesse Colman, and Eric Kalendra National Renewable Energy Laboratory

NREL is a national laboratory of the U.S. Department of Energy Office of Energy Efficiency \& Renewable Energy Operated by the Alliance for Sustainable Energy, LLC

This report is available at no cost from the National Renewable Energy Laboratory (NREL) at www.nrel.gov/publications.

Technical Report

NREL/TP-6A20-64297

July 2015

Contract No. DE-AC36-08GO28308 


\section{Predicting the Response of Electricity Load to Climate Change}

Patrick Sullivan, Jesse Colman, and Eric Kalendra National Renewable Energy Laboratory

Prepared under Task No. WFW8.1000

NREL is a national laboratory of the U.S. Department of Energy Office of Energy Efficiency \& Renewable Energy Operated by the Alliance for Sustainable Energy, LLC

This report is available at no cost from the National Renewable Energy Laboratory (NREL) at www.nrel.gov/publications.

National Renewable Energy Laboratory 15013 Denver West Parkway Golden, CO 80401

303-275-3000 • www.nrel.gov

\section{Technical Report}

NREL/TP-6A20-64297

July 2015

Contract No. DE-AC36-08GO28308 


\title{
NOTICE
}

This report was prepared as an account of work sponsored by an agency of the United States government. Neither the United States government nor any agency thereof, nor any of their employees, makes any warranty, express or implied, or assumes any legal liability or responsibility for the accuracy, completeness, or usefulness of any information, apparatus, product, or process disclosed, or represents that its use would not infringe privately owned rights. Reference herein to any specific commercial product, process, or service by trade name, trademark, manufacturer, or otherwise does not necessarily constitute or imply its endorsement, recommendation, or favoring by the United States government or any agency thereof. The views and opinions of authors expressed herein do not necessarily state or reflect those of the United States government or any agency thereof.

This report is available at no cost from the National Renewable Energy Laboratory (NREL) at www.nrel.gov/publications.

Available electronically at SciTech Connect http:/www.osti.gov/scitech

Available for a processing fee to U.S. Department of Energy and its contractors, in paper, from:

\author{
U.S. Department of Energy \\ Office of Scientific and Technical Information \\ P.O. Box 62 \\ Oak Ridge, TN 37831-0062 \\ OSTI http://www.osti.gov \\ Phone: 865.576.8401 \\ Fax: 865.576.5728 \\ Email: reports@osti.gov
}

Available for sale to the public, in paper, from:

\author{
U.S. Department of Commerce \\ National Technical Information Service \\ 5301 Shawnee Road \\ Alexandria, VA 22312 \\ NTIS http://www.ntis.gov \\ Phone: 800.553 .6847 or 703.605 .6000 \\ Fax: 703.605.6900 \\ Email: orders@ntis.gov
}




\begin{abstract}
Our purpose is to develop a methodology to quantify the impact of climate change on electric loads in the United States. We perform simple linear regression, assisted by geospatial smoothing, on paired temperature and load time-series to estimate the heating- and coolinginduced sensitivity to temperature across 300 transmission zones and 16 seasonal and diurnal time periods. The estimated load sensitivities can be coupled with climate scenarios to quantify the potential impact of climate change on load, with a primary application being long-term electricity scenarios. The method allows regional and seasonal differences in climate and load response to be reflected in the electricity scenarios. While the immediate product of this analysis was designed to mesh with the spatial and temporal resolution of a specific electricity model to enable climate change scenarios and analysis with that model, we also propose that the process could be applied for other models and purposes.
\end{abstract}




\section{Introduction}

Much research has been devoted to modeling the relationship between weather and electricity load. In order to forecast power requirements on a day-to-day basis, utilities and Regional Transmission Organizations (RTOs) have been refining their understanding of this interaction for decades. However, these forecasting models are typically region-specific, and they seldom appear in the public domain (Sailor and Muñoz 1997). Energy researchers began to study this relationship in the mid-1980s specifically to understand the potential impact of climate variability on electricity load. The majority of the literature we reviewed examines the changing relationship between temperature and load over time as a result of either climate change or technological change. Related work develops weather-dependent energy models for buildings.

Research into the relationship between temperature and load exists in many forms, for numerous geographic regions, and through a variety of analytical techniques. Sailor, one of the most widely quoted authors on the topic, employs U.S. state-level, monthly weather and load data (Sailor and Muñoz 1997, Sailor 2001, and Sailor 2006, although the latter uses a city-level correction factor). Schaeffer (2012) summarizes much of the temperature-load analysis across several U.S. states, Canadian provinces, and in many countries and cities around the world. In the United States, the Federal Energy Regulatory Commission (FERC) developed a state- and utility-level model of the relationship between load and cooling degree hours in order to calculate the potential for demand response. This work accounted for regional air conditioning penetration levels ${ }^{1}$ (FERC 2009). Isaac and van Vuuren (2009) aggregate global data to project global annual space-conditioning energy demands through 2050. Their work also considers trends in national economic development and technology penetration. Similarly, Hekkenberg (2009) showed that in the Netherlands, temperature dependence of load increased between the 1970s and the 1990s and that the increase could be explained by an increasing penetration of cooling technologies.

One of the challenges in modeling this relationship is addressing the correlation across the range of temperatures in the "comfort zone." At low temperatures there is a clear negative correlation between energy use and temperature, and at high temperatures the relationship is clearly positive. However, across the range of comfortable temperatures, the temperature-load correlation is less distinct. Moreover, comfort zones vary by region (Isaac and van Vuuren 2008). Moral-Carcedo and Vicéns-Otero (2005) compares smooth transition regression, switching regression, and threshold regression which are all statistical approaches to address this transitional temperature range.

Several authors have analyzed and compared modeling techniques used to estimate load sensitivity to temperature. Tso and Yau (2007) compare decision trees, artificial neural networks, and regression models based on model accuracy in predicting residential energy consumption in Hong Kong. Swan and Ugursal (2009) compare top-down to bottom-up models of residential energy consumption. The former relate energy to macro factors and the latter aggregate energy use across household sizes and types. Zhou, Eom, and Clarke (2013) and Zhou et. al (2014) use climate projections of heating and cooling degree days to project changes in building energy requirements for use in the GCAM integrated assessment model.

\footnotetext{
${ }^{1}$ Only cooling loads were analyzed because demand response is most valuable during annual peak loads, which typically occur during hot summer days.
} 
Our analysis uses simple least-squares regression to calculate load sensitivity parameters at finely resolved spatial and temporal scales. We use a geostatistical model to augment the regression and spatially smooth the estimates. The temperature sensitivity coefficients allow us to produce alternative load growth futures that incorporate temperature projections from climate models in order to estimate the impact of climate change on U.S. electricity load. This work provides a demand-side lever for electric sector capacity expansion models exploring potential impacts of climate change. 


\section{Methodology}

\subsection{Data}

The core of this analysis is a comparison of hourly electrical load to surface air temperatures for the years 2005 and 2006, akin to that done by Denholm and Ong (2012). The load data for this study was compiled by Platts but is publicly available through FERC Form 714. The dataset includes hourly load data for 300 entities comprised of utilities, market sub-regions, or balancing authority areas, and these entities are collectively referred to here as "transmission zones." The transmission zones span the continental United States except for two small "missing" transmission zones in the Midwest (the two gray regions in Figure 4). The peak load varies considerably across transmission zones. Over $75 \%$ of the transmission zones have peak loads less than 2,500 MW. The smallest transmission zone peak is $5 \mathrm{MW}$ (Florida Power \& Light South), and the largest is over 30,000 MW (Commonwealth Edison in Illinois). The mean peak load is 2,600 MW, and the median peak is $1,100 \mathrm{MW}$.

We paired the transmission zone load time-series with hourly surface air temperature time-series for the same years for sites selected from the updated 1991-2010 National Solar Resource Database (NSRDB). ${ }^{2}$

\subsubsection{Data filtering}

We created one filter prior to the regression analysis. Data pairs for which the temperature is in the "comfort zone" range of $16-20^{\circ} \mathrm{C}$ were excluded. At extreme temperatures, non-reference load is clearly induced by either heating or cooling demand. However, there is a range of temperatures across which people are comfortable and do not need space conditioning, making non-reference load hard to attribute to either heating or cooling. Isaac and van Vuuren (2009) describe regional comfort zone variation. Furthermore, the comfort zone may vary depending on recent temperatures. For instance, following a week of $10^{\circ} \mathrm{C}$ temperatures, $16^{\circ} \mathrm{C}$ might feel relatively pleasant, so residents may decide to turn the heat off. However, following a week of $22^{\circ} \mathrm{C}$ temperatures, $16^{\circ} \mathrm{C}$ might feel cold and residents may turn on the heat. Thus, a range of temperatures between $16^{\circ} \mathrm{C}$ and $20^{\circ} \mathrm{C}$ are observed through which the load-temperature relationship is much noisier, and we exclude the data in this range when performing the regression.

\subsection{Estimation of Temperature-Load Sensitivity Parameters for ReEDS Application}

The Regional Energy Deployment System (ReEDS) model is an electricity system capacity expansion model, described below. To enable ReEDS to explore electricity system scenarios that include a dynamic climate, this project seeks to develop a methodology for transforming a climate future (temperature trends) into estimated changes in electrical load patterns.

First, we derive raw parameters relating temperature to heating and cooling loads across regions and time-slices. Throughout, "time-slice" refers to the intra-year temporal resolution in ReEDS; a ReEDS year includes 17 time-slices composed of four representative diurnal time periods (morning, afternoon, evening, and night) per season plus a "superpeak" comprised of the highest

\footnotetext{
${ }^{2}$ http://rredc.nrel.gov/solar/old_data/nsrdb/1991-2010/.
} 
40 hours of electricity load in a year. Next, these parameters are spatially smoothed using a conditional autoregression (CAR) model. Finally, the smoothed parameters for 300 transmission zones are redistributed into the 134 ReEDS balancing areas.

\subsubsection{Raw Temperature-Load Sensitivity Parameters}

With hourly load and temperature data for 300 transmission zones in 2005 and 2006, we determine the temperature-sensitive load in each transmission zone using the following steps.

1. Calculate the "temperature-neutral" load profile for weekdays and weekend days.

Denholm and Ong (2012) provided the method for estimating the temperature-neutral hourly load profile. For weekdays (excluding holidays), they found the year's five lowest electricity demand days, removed the two lowest demand days, and took the hourly average of the remaining three days to be the temperature-neutral load profile. For weekend days, the three lowest demand days were found, the lowest single day was dropped, and the hourly averages from the remaining two days compose the temperature-neutral weekend profile.

2. For each hour, subtract the temperature-neutral load from actual load to estimate the temperature-dependent load.

Figure 1 shows a typical daily summer load profile for the Central Illinois Public Service. The lightly shaded temperature-neutral load is estimated as described in step 1.

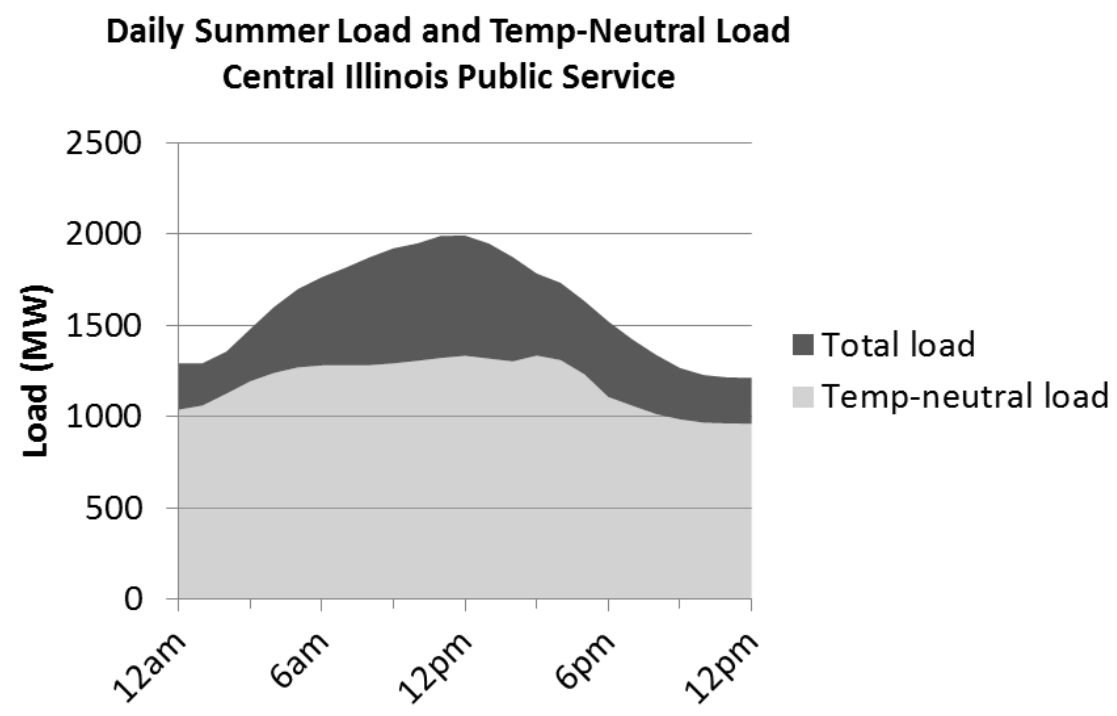

Figure 1. Comparison of actual load and estimated temperature-neutral load for a typical region on a single summer day. The dark-shaded area represents the additional load induced by high ambient temperatures.

3. Convert hourly temperatures and temperature-dependent load to averages for each timeslice-day.

To smooth potential over-specification by time of day, we averaged hourly temperature and temperature-dependent load by ReEDS time-slice within each day. Thus, for regression (step 4) 
each region/time-slice bucket comprises roughly 180 characteristic load-temperature pairs: one for each day, for two years of three-month seasons. ${ }^{3}$

\section{Regress time-slice temperature-dependent heating and cooling loads against time-slice temperature.}

Figure 2 shows the temperature vs. temperature-dependent load for all time slices in a typical region, and Figure 3 shows scatterplots of temperature vs. temperature-dependent load for each time-slice in that region. These scatterplots demonstrate the characteristic V shape of temperature-load relationships, with deviations in temperature away from the neutral zone resulting in higher loads. The best fit lines with slopes are shown for available data above $20^{\circ}$ (cooling line) and below $16^{\circ}$ (heating line). Data between $16^{\circ}$ and $20^{\circ}$ are shown in Figure 2 but excluded from the regression analysis. The slope of each line is the regression coefficient estimating load sensitivity to warm and cool weather in each time-slice. We performed these regressions for each transmission zone and time-slice, resulting in $300 \times 16 \times 2$ heating and cooling sensitivity coefficients.

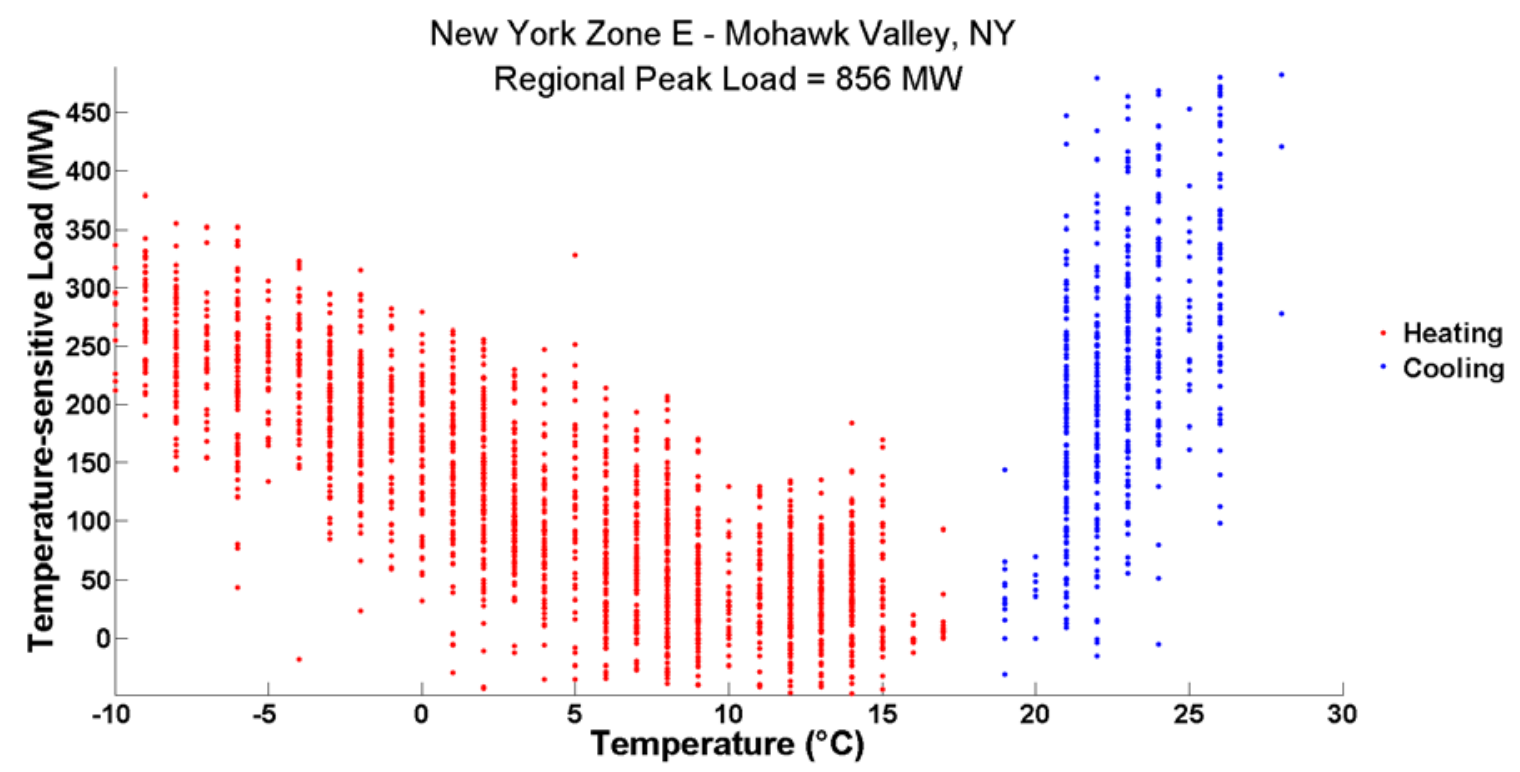

Figure 2. Temperature and temperature-dependent load scatterplot for a region in New York. All time-slices are overlaid in this chart whereas Figure 3 shows each time-slice alone. Each data point represents average temperature and load a single diurnal period: morning, afternoon, evening, and overnight for one day.

After this regression, we undertook three categories of data refinement and cleaning.

First, there are some regions and time-slices for which heating and/or cooling data is sparse. For example, there are very few heating-regime hours in Florida during the summer from which to estimate the region's sensitivity to cold temperatures. When fewer than five data points are available in a particular transmission zone and time-slice, we do not generate a raw sensitivity parameter.

\footnotetext{
${ }^{3}$ ReEDS winter is four months long, fall only 2 months. The number of data points per season is set accordingly.
} 
Second, there was one region where the V-shaped scattering was offset from the typical neutral temperature range as if there had been an error in temperature reporting. Unable to ascertain the actual cause of the offset, we chose to shift the distribution in line with the neutral temperature range.

Temperature $\left({ }^{\circ} \mathrm{C}\right)$ and temperature-dependent load by time-slice

(MW) New York Zone E - Mohawk Valley
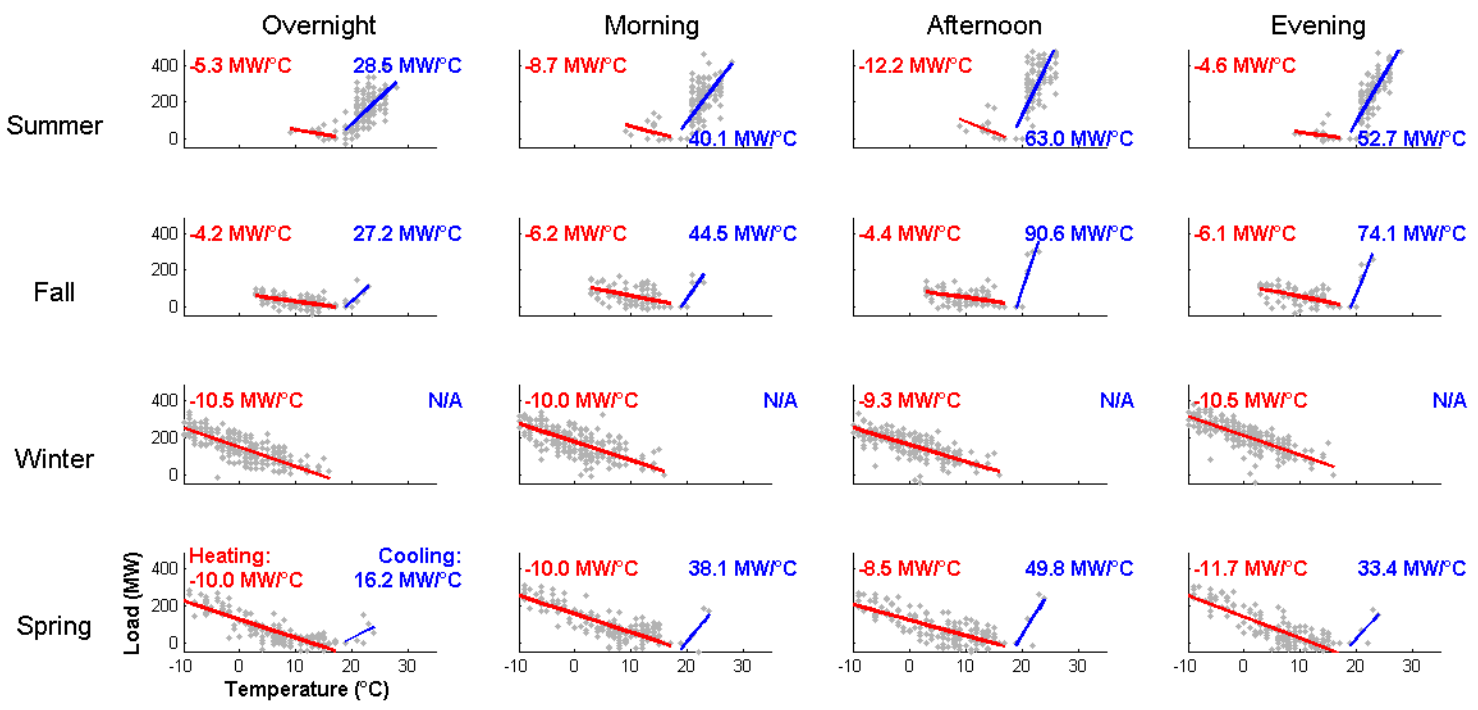

Figure 3. Regional data from the New York Zone E transmission zone, broken into time-slice components. The numbers in red and blue are heating and cooling load sensitivity parameters.

Finally, a subset of small-load regions showed a double-V phenomenon, with one distinct V shape at one load level and a second $\mathrm{V}$ shifted up by some quantity from the first, a phenomenon that could have been caused, for instance, by adding or subtracting a large load to the transmission zone partway through the recorded interval. Indeed, each of the "V"s could be approximately separated into an earlier and later time period. In each case, the "V"s were roughly parallel, so we calculated the slope from whichever $\mathrm{V}$ provided more data.

\subsubsection{Spatial Smoothing of Raw Parameters Using CAR}

Initial estimates for heating and cooling sensitivities were calculated individually for each transmission zone, without knowledge of any other location, and produced a patchy, inconsistent map of sensitivities. To reduce spatial variation and strengthen estimates for zones with low confidence, we applied a conditional autoregression model (CAR) to the raw heating and cooling sensitivities across transmission zones and within each time-slice. This model $\left(\bar{Y}=Y^{*}+\varepsilon\right)$ assumes that the raw parameter $\left(Y_{i}\right)$ is estimating the true effect $\left(Y^{*}\right)$ with some error $(\varepsilon)$, and the error is quantified by the given standard error: $\epsilon_{i} \sim N\left(0, \sigma_{i}\right)$. To spatially smooth the estimates, the model assumes that the true sensitivity at a given location is equal to the average of those of its neighbors. ${ }^{4}$ The CAR and spatial smoothing algorithms do not fill data gaps for transmission

\footnotetext{
${ }^{4}$ We define neighbors as those regions that share an edge or vertex.
} 
zones with no data, but regional aggregation for a specific tool such as ReEDS can assume that sensitivities in these transmission zones are the same as the average across other transmission zones in the aggregated region.

The model is fit using Markov chain Monte Carlo (MCMC) simulation. The MCMC is run for 5000 iterations using the first or 200 iterations for burn in. We update $Y^{*}$ as a block to limit the required burn-in. The vector of $\bar{Y}^{*}$ resulting from each of the 32 CAR models (heating and cooling for 16 time-slices) is taken as the smoothed temperature sensitivities for the transmission zones for the time-slice. Figure 4 and Figure 5 show examples of raw and smoothed cooling and heating sensitivity. Time-slices and heating/cooling sensitivity parameters retain independence from each other through the CAR model process.
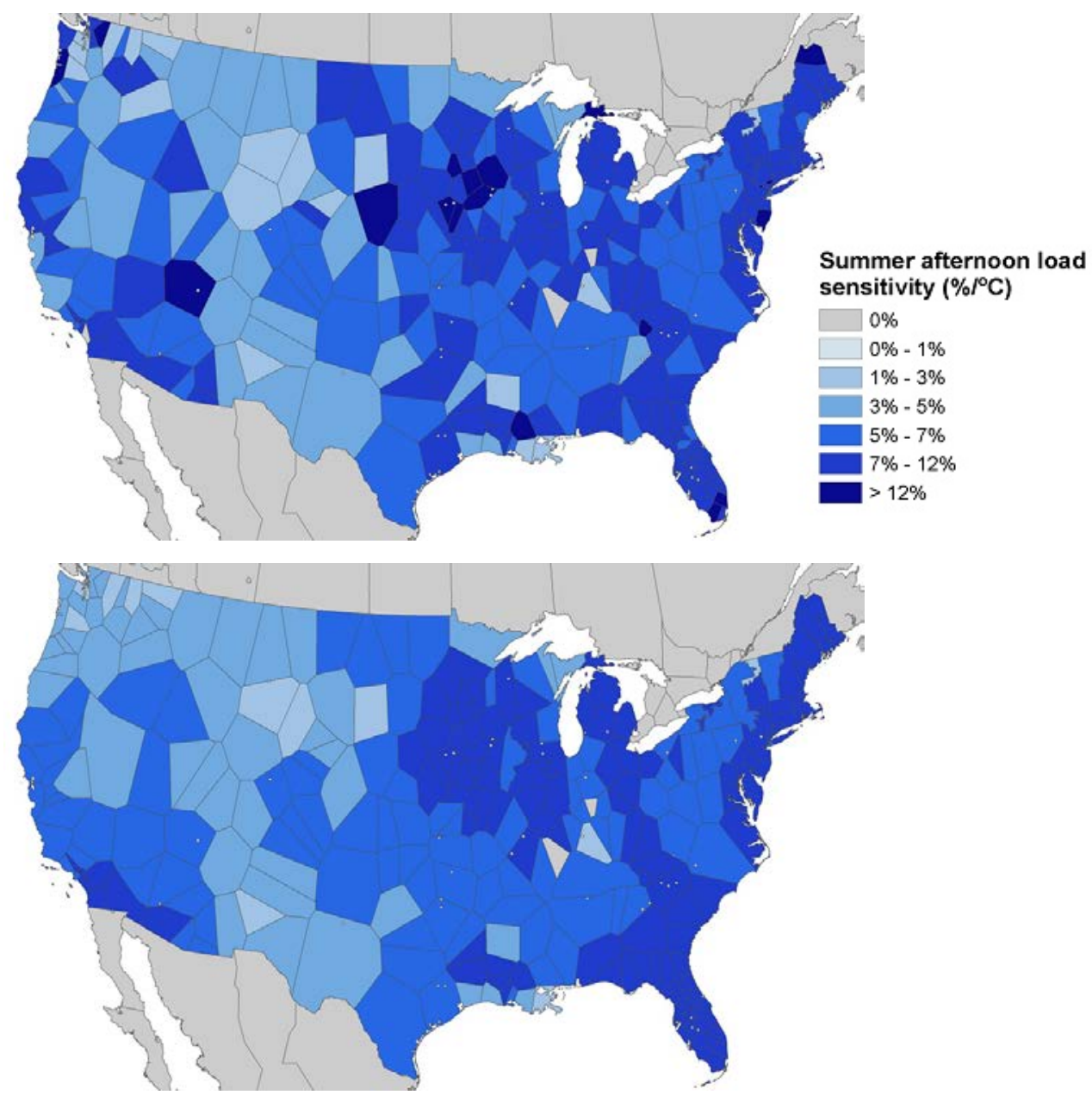

Figure 4. Cooling load sensitivity parameters for summer afternoon time-slice. Maps show raw parameters (top) and spatially smoothed parameters (bottom). Points represent transmission zones that are individual cities.

Both heating and cooling sensitivities display regional and seasonal differences. The South, Midwest, and Northeast are particularly sensitive to summer heat, while the Northwest and Mountain West are relatively insensitive (Figure 4). This effect is likely climate-related: the Northwest is a temperate region, so there may be lower adoption of space-cooling; and the 
Mountain West is comparatively arid, allowing for cool nights and evaporative coolers to reduce the need for refrigeration-cycle air conditioning. For heating, Florida shows much higher sensitivity to overnight cold temperatures than the rest of the country (Figure 5). The low frequency of cold weather in Florida likely makes infrastructure poorly adapted to the occasional cold snap: poorly-insulated buildings, lack of furnaces shifts load to inefficient space-heaters, etc. In contrast, in the Northeast, despite cold winters, sensitivity is low: a sizeable fraction of heating in the region is by heating oil or natural gas (Amato et al. 2005), thereby isolating such heating from electricity demand.
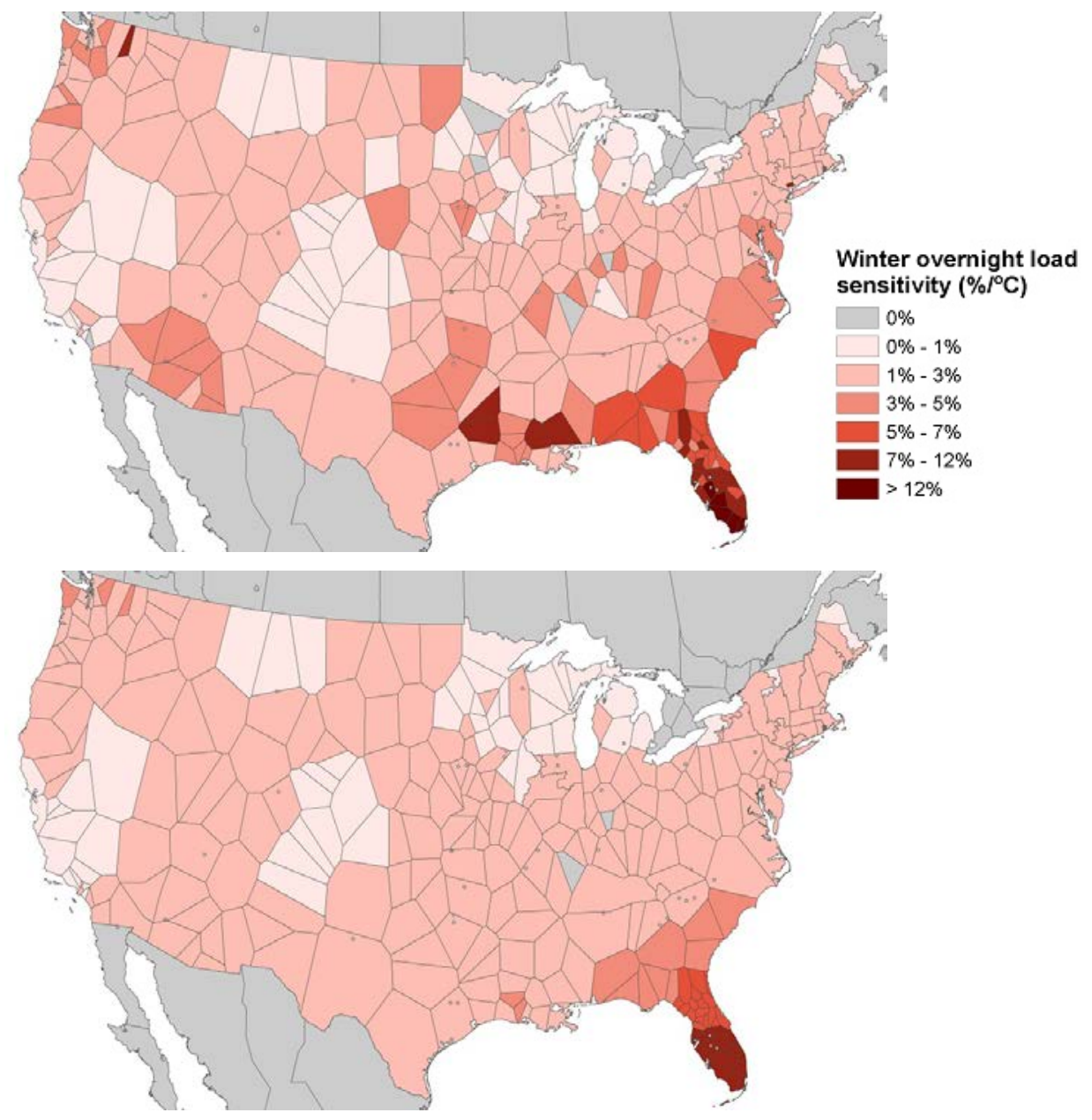

Figure 5. Heating load sensitivity parameters for winter overnight time-slice. Maps show raw parameters (top) and spatially smoothed parameters (bottom). Points represent transmission zones that are individual cities.

\subsection{Projecting Total Electric Load Under Climate Scenarios}

The purpose of the current effort is to develop electricity demand input data for the ReEDS model (Short et al. 2011) that reflect a changing climate. ReEDS is a linear optimization program that models U.S. electric sector capacity expansion through 2050, and its resolution and model structures informed our choice of regression model design and the ultimate product described in these pages. ReEDS uses a hierarchy of geographical divisions including 134 balancing areas at which it must serve load, so we worked at a spatial resolution we could apply to ReEDS 
balancing areas. Baseline electricity demand in ReEDS is specified at each balancing area for each time-slice using projections from the U.S. Energy Information Administration Annual Energy Outlook (AEO). ${ }^{5}$ The framework presented here adjusts the AEO baseline load —using the heating and cooling sensitivities and long-term climate projections - to incorporate effects of climate change. Because it is constructed atop the baseline AEO load projection, the projections may duplicate any temperature-load effects implicit in the AEO reference load and should therefore be considered in comparison rather than as absolute.

The final step with the sensitivities was to redistribute the 300 smoothed transmission zone heating and cooling parameters for each time-slice into 134 ReEDS balancing areas using population-based weighting.

The other component needed for load adjustment is projections of temperature change by region and time-slice from 2010 to 2050 . We obtained gridded daily temperature estimates across the United States from MIT's Integrated Earth System Model (IGSM; Paltsev et al. 2013). IGSM reports daily average temperature on a 2 degree by 2.5 degree grid from 1980 to 2115 ; for this report, we used a climate change scenario in which radiative forcing stabilizes at $4.5 \mathrm{~W} / \mathrm{m}^{2}$ in 2100 (an RCP4. $5^{6}$ scenario) described by Monier et al (2014). We consolidated the temperatures to seasonal degree day measures at each grid cell, spatially interpolated the gridded degree day estimates to ReEDS balancing areas, and smoothed the degree-day trajectories across our time horizon by fitting a fourth-degree polynomial. This methodology results in smooth paths for heating and cooling degree days (HDD and CDD) for each season and balancing area that describe long-term averages for climate change temperature trends. Truncating the time-series to the ReEDS window (2010-2050) eliminates unstable end effects from the polynomial smoothing.

Once converted to the ReEDS data structure, we can compare the regional, seasonal degree day paths to a static-climate scenario in which the number and distribution of degree days remains at 1990-2010 historical averages. In general, heating degree days decline in the RCP4.5 scenario, and cooling degree days increase relative to a static climate assumption (Figure 6). The change in degree days between the RCP4.5 and static-climate scenarios can be considered the characteristic temperature increase of the climate change scenario. Multiplying the degree day delta $\left({ }^{\circ} \mathrm{C}\right)$ by the temperature sensitivity $\left(\mathrm{MW} /{ }^{\circ} \mathrm{C}\right)$ provides an estimate for the change in time-slice electricity demand (in MW) induced by the changing climate. The overall impact is an increase in annual load, but this method is also able to report spatial and seasonal subtleties that coarser methods overlook. Over most of the country, higher summer temperatures increase both overall load and amplitude of the diurnal load profile - the latter effect exists because temperature sensitivities tend to be higher in summer afternoons than overnight. In the winter, higher temperatures reduce heating loads somewhat.

\footnotetext{
${ }^{5}$ For detailed information about ReEDS load assumptions, see NREL's Renewable Electricity Futures study, volume 3.

${ }^{6} \mathrm{RCP}$ is an acronym for "Representative Climate Pathway"
} 

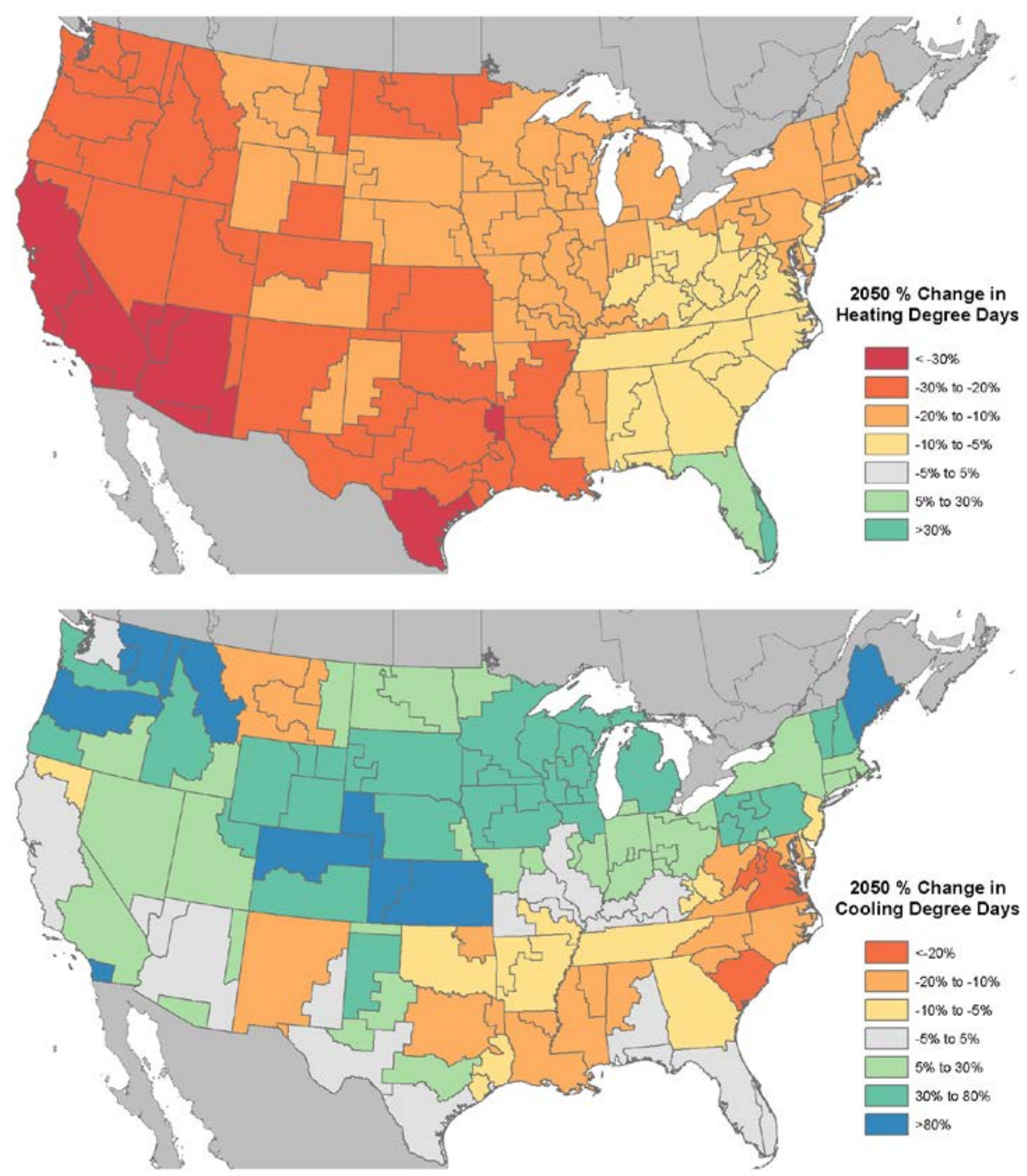

Figure 6. These maps show the geographical distribution of projected annual change in HDD (top) and CDD (bottom). HDD decrease in most regions while CDD increase in most regions except the southeast. 

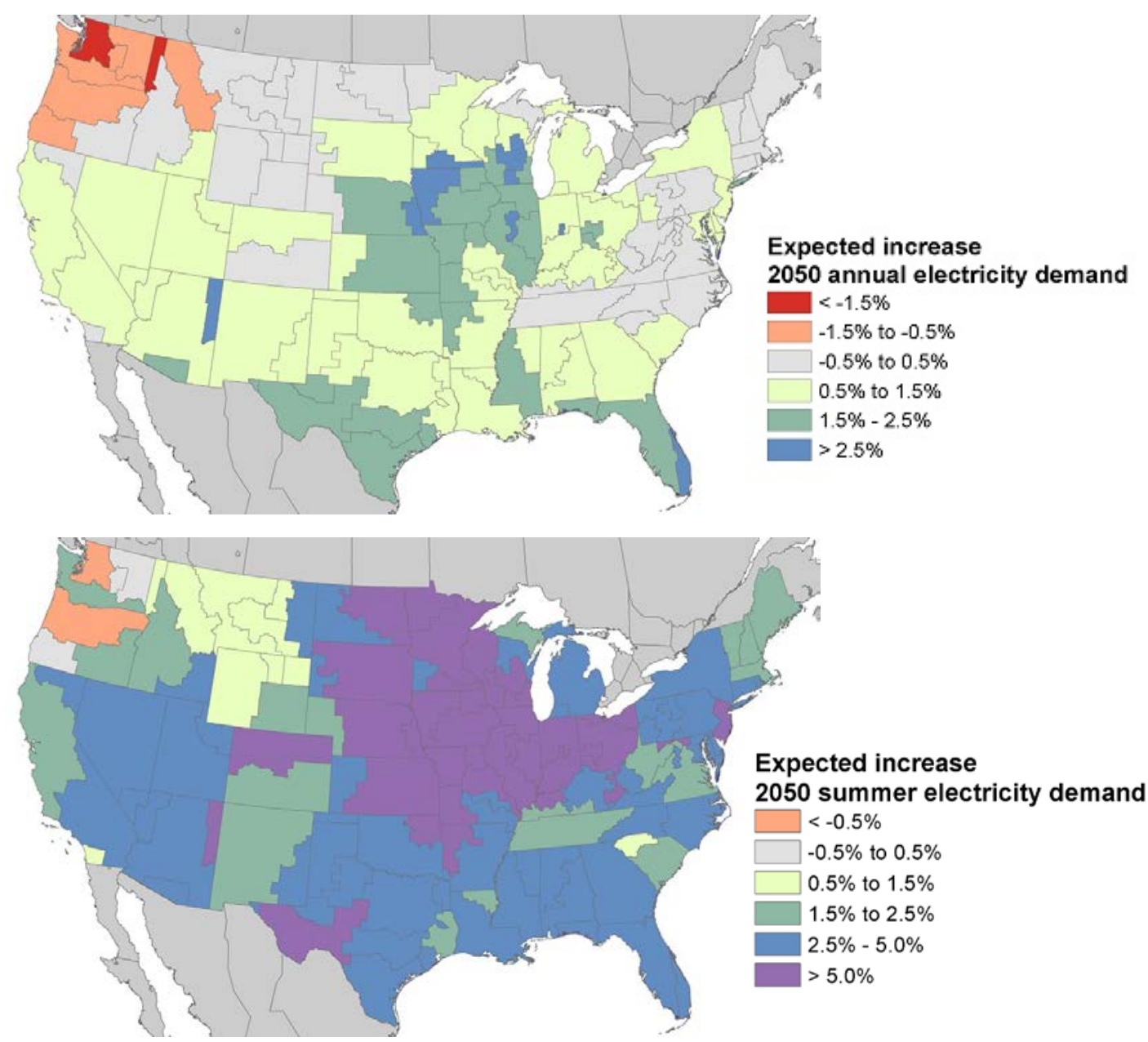

Figure 7. These maps show the geographical distribution of projected annual demand increases (top) and summer demand increases (bottom). The annual changes are smaller because summer increases are counterbalanced by decreased winter heating demands.

Having obtained climate-sensitive load profiles, we can apply them in model scenarios investigating possible impacts of climate change on the U.S. electric sector. Some work using these adjusted profiles is described in McFarland et al. (2015). An advantage of using time-slice dependent factors is that the method can distinguish how the increase in demand is distributed across the year. For the RCP 4.5 scenario, total U.S. annual demand in 2050 increased by roughly $1 \%$ over the static-climate baseline, but summer has a $3 \%$ increase in demand while winter has a slight decrease due to a decline in heating loads. Expected annual peak loads for each balancing area, summed across the country non-coincidently, rise by nearly $5 \%$ with climate change. The method also allows regional differentiation for existing climate, non-uniform climate change, demographics, and technology (traditional electric-heating regions see greater load-reduction in winter than traditional gas- or oil-heating regions).

\subsection{Limitations and Assumptions}

Here we note a few limitations to the work presented. First, to determine temperature-neutral loads, we divided the year into two categories: weekdays and weekend days. Valor et al. (2001) suggest that Mondays and Fridays also have distinct load profiles, which suggests that assessing 
temperature-dependent load using an additional category bin for the "weekend's shoulder" days or performing a regression with day-of-week as a variable could increase fidelity.
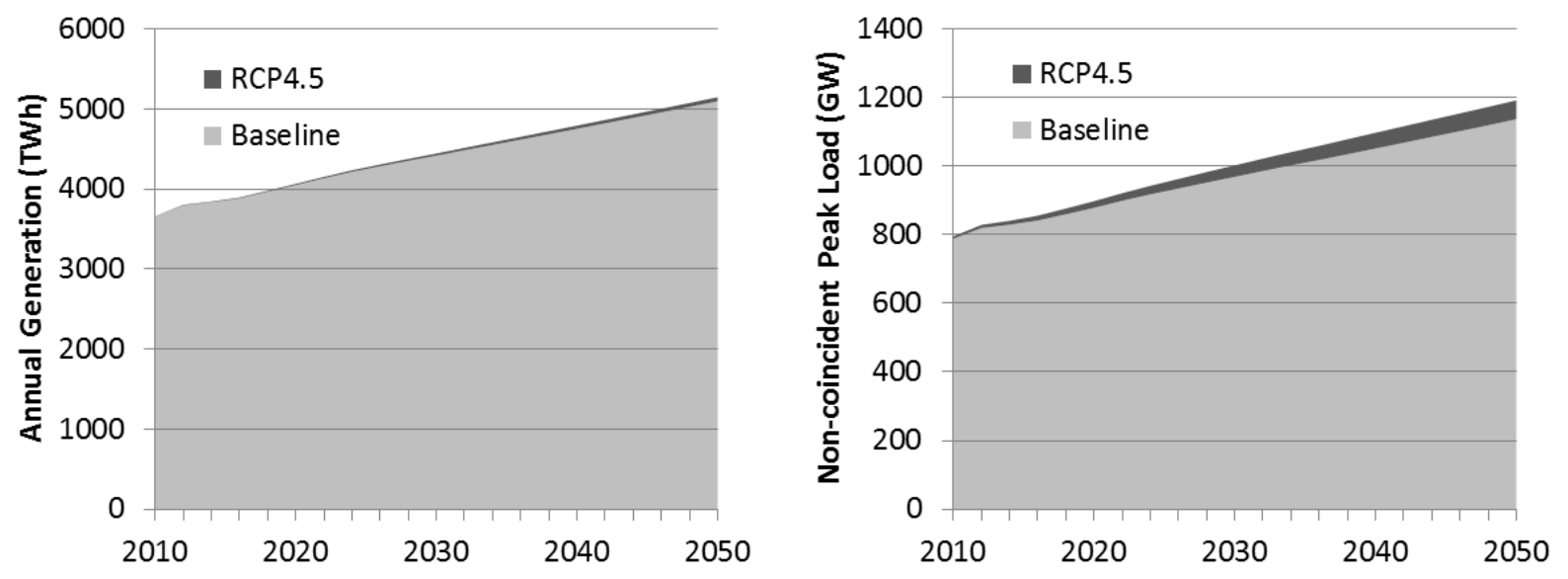

Figure 8. There is a slight $(\sim 1 \%)$ increase in total annual demand from the baseline to RCP4.5 scenario (left). The increase in load is not distributed evenly, however: the summer, and especially the peak hours, see greater-than-average load increases under climate change (right).

Second, implicit in our methodology is the assumption that all loads above our "temperatureneutral loads" are dedicated to temperature-related space conditioning, which is furthermore assumed to be a linear function of dry-bulb temperature. Temperature is the primary driver of weather-dependent load (Park et al. 1991; Chow and Leung, 1996; and Khotanzada et al., 1995), but other variables have been shown to impact load including wind speed, insolation, and humidity. Ignoring these variables may misstate temperature sensitivity.

Third, although the assumption of temperature-dependent load variability largely holds for commercial and residential loads, industrial loads tend to vary instead based on economic drivers. Each of the 300 transmission zones is characterized by an unknown load ratio of temperature-sensitive (residential/commercial) to temperature-insensitive (industrial) loads. We can reasonably expect that our temperature sensitivity parameters would remain accurate if these load ratios were static. However, population shifts and changes in economic activity over time are likely to alter the load ratio, which would alter any load sensitivity parameters that do not distinguish between load sectors.

Fourth, within each region the magnitude of the temperature-dependent load depends on choice of, efficiency of, and access to space conditioning technologies. Our use of load sensitivity parameters assumes that the technologies and behavior at the time of our data collection will remain constant through our model time horizon. We point to three trends that refute this assumption. First, air conditioning penetration has been steadily rising, which should increase load sensitivity to high temperatures. Second, appliance efficiency has been steadily increasing, and this trend should reduce load sensitivity to temperature. Finally, recent declines in natural gas prices and projections of low prices for at least a decade could induce a shift away from electric heating to natural gas heating, reducing the electric load sensitivity to temperature. 
Fifth, in some regions/time-slices there is no available heating or cooling data. For instance, there is little heating data in Florida in the summer. We nonetheless construct heating parameters for Florida using the CAR model. Regions without data are handled when aggregating from transmission zones to ReEDS regions; the ReEDS region load sensitivity is calculated while ignoring the region with no data, then the ReEDS aggregated regional sensitivity is assumed applicable in that region. 


\section{Results}

The RCP4.5 scenario results in an increase in average annual temperature of around $1.6^{\circ} \mathrm{C}$ from 2000-2050, with regional differences across the continent. The projected climate-induced load impact from this method and climate scenario is an increase of roughly $1 \%$ in expected 2050 annual load over the static-climate scenario. There are regional differences, as shown in Figure 6, but they remain within a compact range of a $2 \%$ decrease to a $3 \%$ increase. Seasonal differences are somewhat more dramatic, with summer afternoons having strong cooling-related demand growth.

We are able to compare our results directly to previous studies that suggest our estimates of load increase are conservative. Sailor (2001) reported expected impacts of $1{ }^{\circ} \mathrm{C}, 2^{\circ} \mathrm{C}$, and $3{ }^{\circ} \mathrm{C}$ temperature increases for a subset of states, for residential and commercial electricity differences. Table 1 compares Sailor's $1^{\circ} \mathrm{C}$ and $2^{\circ} \mathrm{C}$ estimates to this study's results. While this study predicts smaller increases in Florida, California, and Texas, the five other states match up well between the two studies, including Washington, which both studies expect to experience reduced load with increased temperatures in this range. A possible reason for the larger load growth in southern states in the Sailor study is that it explicitly allowed increased adoption of air conditioning.

Table 1. Percent Increase in Load Attributable to Noted Average Air Temperature Increase

\begin{tabular}{|c|c|c|c|c|c|}
\hline & \multicolumn{2}{|c|}{ Sailor Residential } & \multicolumn{2}{|c|}{ Sailor Commercial } & \multirow{2}{*}{$\begin{array}{l}\text { This Stud } \\
\Delta T=1.6^{\circ} \mathrm{C}\end{array}$} \\
\hline & $\Delta T=1^{\circ} \mathrm{C}$ & $\Delta T=2^{\circ} \mathrm{C}$ & $\Delta T=1^{\circ} \mathrm{C}$ & $\Delta T=2^{\circ} \mathrm{C}$ & \\
\hline California & 1.8 & 4.1 & 2.3 & 4.8 & $0.0-1.5$ \\
\hline Florida & 5.3 & 11.6 & 2.4 & 5 & $2.1-2.5$ \\
\hline Illinois & 1.6 & 3.8 & 0.9 & 1.9 & $1.7-4.9$ \\
\hline Louisiana & 0.7 & 1.6 & 1.4 & 3 & $0.8-0.9$ \\
\hline New York & 0.4 & 0.9 & 0.8 & 1.6 & $0.6-1.6$ \\
\hline Ohio & 0.7 & 1.9 & 1.2 & 2.5 & $1.0-2.4$ \\
\hline Texas & 2.6 & 5.6 & 1.1 & 2.3 & $0.9-2.2$ \\
\hline Washington & -3.9 & -7.2 & -0.4 & -0.3 & $-2.0-0.7$ \\
\hline
\end{tabular}

Comparison between selected state results from Sailor (2001) and this study. Percent ranges for this study span the range of values for balancing areas within each state.

Sue Wing (2014) found much higher load sensitivity in his econometric analysis: a 7.6\% annual demand increase nationwide by 2050 under a slightly warmer A2 scenario. That regression separates residential, commercial, and industrial loads and computes sensitivities separately for each. Also, and perhaps critically, the analysis allows nonlinear relationships between temperature deviation from the comfort zone and load, with especially high temperatures inducing faster load growth. We saw limited evidence for such a nonlinear relationship in our regression, but with only two years of hourly temperatures, such data points were very limited. Sue Wing based his regression on 20 years of temperature-load relationships. 


\section{Conclusion}

This study describes a methodology for producing climate-dependent load projections that can be used in long-term electricity system planning models. We follow on numerous previous studies that assert sensitivity of load to temperature can be estimated by regressing hourly loads against air temperatures. Our work and previous studies have shown clear correlations between temperature deviations from a room-temperature comfort zone and an increase in electrical demand. The primary difference in this work is that it was designed to mesh with the spatial and temporal resolution of a specific electricity model to enable climate change scenarios. As a result, it reveals information about regional and temporal patterns in space-conditioning load that are rare in the literature but necessary for ReEDS scenario development.

It is clear that there are factors beyond ambient temperature that affect load, and that there are also long-term considerations involving population, technology advancement and adoption patterns, and fraction of demand for space conditioning that will determine how space conditioning loads change over coming decades. Other studies have included attempts at projecting air conditioning adoption rates and efficiencies to improve on the assumption of stasis. We retain static assumptions for these characteristics, which may explain this study's somewhat lower sensitivity estimates than other comparable work.

Temperature projections from a global climate model offer a backdrop on which the ReEDS temperature-dependent loads are applied. Pairing seasonal temperature expectations with the sensitivities developed for this study produce climate-induced load changes. Only one climate future, the RCP4.5, is discussed in this paper, but the method was also used for alternate RCP scenarios for the Climate Change Impacts and Risk Analysis (CIRA) project described in McFarland et al. (2015). In the RCP4.5 scenario, loads increase slightly above static-climate projections, but more important is that load perturbations are heterogeneous across regions and time, reflecting regional and seasonal patterns in population, technology, and climate. 


\section{References}

Amato, Anthony D., Matthias Ruth, Paul Kirshen, and James Horwitz. 2005. "Regional energy demand responses to climate change: methodology and application to the Commonwealth of Massachusetts." Climatic Change 71:175-201.

Chow, T.W.S., and C.T. Leung. 1996. "Neural Network Based Short-Term Load Forecasting Using Weather Compensation." IEEE Transactions on Power Systems 11:1736-1742.

Denholm, Paul, Sean Ong, and Chuck Booten. 2012. Using Utility Load Data to Estimate Demand for Space Cooling and Potential for Shiftable Loads. NREL/TP-6A20-54509. Golden, CO: National Renewable Energy Laboratory.

FERC (Federal Energy Regulatory Commission). 2009. A National Assessment of Demand Response Potential. FERC Staff Report prepared by The Brattle Group, Freeman Sullivan, \& Co, and Global Energy Partners. Washington, DC: Federal Energy Regulatory Commission.

Hekkenberg, M., R.M.J. Benders, H.C. Moll, and A.J.M. Schoot Uiterkamp. 2009 "Indications for a Changing Electricity Demand Pattern: The Temperature Dependence of Electricity Demand in the Netherlands." Energy Policy 37:1542-1551. doi:10.1016/j.enpol.2008.12.030.

Isaac, Morna, and Detlef P. van Vuuren. 2009. "Modeling Global Residential Sector Energy Demand for Heating and Air Conditioning in the Context of Climate Change." Energy Policy 37:507-521. doi:10.1016/j.enpol.2008.09.051.

Khotanzad, A., Rey-Chue Hwang, A. Abaye, and D. Maratukulam. 1995. "An Adaptive Modular Artificial Neural Network Hourly Load Forecaster and Its Implementation at Electric Utilities." IEEE Transactions on Power Systems 10:1716-1722. doi:10.1109/59.466468.

McFarland, J., Zhou, Y., Clarke, L., Sullivan, P., Jaglom, W., Colman, J., Patel, P., Eom, J., Kim, S.H., Kyle, G.P., Colley, M., Schultz, P., Venkatesh, B., Haydel, J., Miller, R., Creason, J. (2015). "Impacts of rising air temperatures and emissions mitigation on electricity demand and supply in the United States: a multi-model comparison." Climatic Change. doi: 10.1007/s10584015-1380-8. (in press)

Monier, Erwan, Xiang Gao, Jeffrey R. Scott, Andrei P. Sokolov, and C. Adam Schlosser. 2014. "A framework for modeling uncertainty in regional climate change." Climatic Change June 2014. doi:10.1007/s10584-014-1112-5.

Moral-Carcedo, Julián, and José Vicéns-Otero. 2005. "Modelling the Non-Linear Response of Spanish Electricity Demand to Temperature Variations.” Energy Economics 27:477-494. doi:10.1016/j.eneco.2005.01.003.

Paltsev, S., E. Monier, J. Scott, A. Sokolov, and J.M. Reilly. (2013). "Integrated economic and climate projections for impact assessment." Climatic Change October 2013. doi:10.1007/s10584013-0892-3

Park, Dong C., M.A. El-Sharkawi, R.J. Marks, L.E. Atlas, and M.J. Damborg. 1991. "Electric Load Forecasting Using an Artificial Neural Network." IEEE Transactions on Power Systems $6: 442-449$. 
Sailor, David J., and J.R. Munoz. 1997. "Sensitivity of Electricity and Natural Gas Consumption to Climate in the U.S.A.—methodology and results for eight states." Energy 22:987-998.

Sailor, David J. 2001. "Relating Residential and Commercial Sector Electricity Loads to Climate_evaluating State Level Sensitivities and Vulnerabilities.” Energy 26:645-657.

Sailor, David J., and Chittaranjan Vasireddy. 2006. "Correcting Aggregate Energy Consumption Data to Account for Variability in Local Weather." Environmental Modelling \& Software 21:733-738. doi:10.1016/j.envsoft.2005.08.001.

Schaeffer, Roberto, Alexandre Salem Szklo, André Frossard Pereira de Lucena, Bruno Soares Moreira Cesar Borba, Larissa Pinheiro Pupo Nogueira, Fernanda Pereira Fleming, Alberto Troccoli, Mike Harrison, and Mohammed Sadeck Boulahya. 2012. "Energy Sector Vulnerability to Climate Change: A Review.” Energy 38: 1-12. doi:10.1016/j.energy.2011.11.056.

Short, Walter, Patrick Sullivan, Trieu Mai, Matthew Mowers, Caroline Uriarte, Nate Blair, Donna Heimiller, and Andrew Martinez. 2011. Regional energy deployment system (ReEDS). NREL/TP-6A20-46534. Golden, CO: National Renewable Energy Laboratory.

Sue Wing, I. (2013). "Climate change and US electric power.” Paper presented at the American Economic Association Conference, Philadelphia, Pennsylvania, January 4. Cited with permission.

Swan, Lukas G., and V. Ismet Ugursal. 2009. "Modeling of End-Use Energy Consumption in the Residential Sector: A Review of Modeling Techniques." Renewable and Sustainable Energy Reviews 13:1819-1835. doi:10.1016/j.rser.2008.09.033.

Tso, Geoffrey K.F., and Kelvin K.W. Yau. 2007. "Predicting Electricity Energy Consumption: A Comparison of Regression Analysis, Decision Tree and Neural Networks.” Energy 32:17611768. doi:10.1016/j.energy.2006.11.010.

Valor, Enric, Vicente Meneu, and Vicente Caselles. 2001. "Daily Air Temperature and Electricity Load in Spain.” Journal of Applied Meteorology 40, no. 8 (2001): 1413-1421.

Xu, Peng, Yu Joe Huang, Norman Miller, Nicole Schlegel, and Pengyuan Shen. 2012. "Impacts of Climate Change on Building Heating and Cooling Energy Patterns in California." Energy 44:792-804. doi:10.1016/j.energy.2012.05.013.

Zhou, Yuyu, Jiyong Eom, and Leon Clarke. 2013. "The effect of global climate change, population distribution, and climate mitigation on building energy use in the U.S. and China." Climate Change 199:979-992. doi:10.1007/s10584-013-0772-x.

Zhou, Yuyu, Leon Clarke, Jiyong Eom, Page Kyle, Pralit Patel, Son H. Kim, James Dirks, Erik Jensen, Ying Lui, Jennie Rice, Laurel Schmidt, and Timothy Seiple. 2014. "Modeling the effect of climate change on U.S. state-level buildings energy demands in an integrated assessment framework." Applied Energy 113:1077-1088. doi:10.1016/j.apenergy.2013.08.034. 